http://jmscr.igmpublication.org/home/

ISSN (e)-2347-176x ISSN (p) 2455-0450

crossref DOI: https://dx.doi.org/10.18535/jmscr/v8i5.30

Journal Of Medical Science And Clinical Research

\title{
Management of Moderate to Severe Marcus Gunn Syndrome by Levator Disinsertion and Frontalis Sling of Affected Eye
}

\author{
Authors \\ Dr (Prof) P.Rawat ${ }^{1}$, Dr Awani Dubey ${ }^{*}$, Dr Shikha Kudape ${ }^{3}$, Dr Upali Tiwari ${ }^{4}$ \\ ${ }^{1}$ Professor, Department of ophthalmology, M.G.M. Medical College \& M.Y. Hospital, Indore (M.P.) \\ ${ }^{2,3,4}$ Resident Doctor, Department of Ophthalmology, Mahatma Gandhi Memorial Medical College, M.Y. \\ Hospital Indore (M.P.) 452001, India \\ *Corresponding Author \\ Dr Awani Dubey
}

\begin{abstract}
Purpose: To describe the treatment of Marcus gunn jaw winking ptosis by levator disinsertion and silicone sling surgery

Methods: A 12-year old female patient presented with drooping of left upper lid since birth with defective vision. She had a mild chin elevation.

In this case, levator muscle was disinserted and the eyelid was coupled to the frontalis muscle using a sling made of a synthetic material. By recruiting the frontalis muscle to raise the eyelids, this procedure relieved the dysfunctional levator from contributing to eyelid elevation.

Results: Following surgery, the lid lag, which was quite marked at the beginning, was much reduced after three months. The lagophthalmos was minimal. A good symmetrical lift with a good lid fold was obtained. There were no post-operative complications like suture abcess, overcorrection or under correction Conclusions: Surgical treatment of mild to moderate marcusgunn jaw winking ptosis could be done with affected eye levator disinsertion with frontalis sling surgery rather than operating on both eyes.
\end{abstract}

\section{Introduction}

Marcus Gunn syndrome is characterized by aberrant innervation between cranial nerve III and $\mathrm{V}$ resulting in synkinetic movements of the levator palpebrae superioris and the ipsilateral pterygoid muscles.

Eyelid ptosis repair with levator disinsertion and concomitant frontalis suspension may be performed for a symptomatic jaw wink associated with Marcus Gunn syndrome as well as severe unilateral, poor levator ptosis. The synkinetic movement can be seen during infancy as variable upper eyelid retraction with opening of the mouth, chewing, and sucking. Lateral, side-to-side jaw movements may also bring about the jaw wink associated with this syndrome.

\section{Case Report}

Marcus Gunn syndrome is characterized by aberrant innervation between cranial nerve III and $\mathrm{V}$ resulting in synkinetic movements of the levator palpebrae superioris and the ipsilateral pterygoid muscles.

Eyelid ptosis repair with levator disinsertion and concomitant frontalis suspension may be performed for a symptomatic jaw wink associated 
with Marcus Gunn syndrome as well as severe unilateral, poor levator ptosis. The synkinetic movement can be seen during infancy as variable upper eyelid retraction with opening of the mouth, chewing, and sucking. Lateral, side-to-side jaw movements may also bring about the jaw wink associated with this syndrome.

A 22 year old female presented to ophthalmology department with complaints of drooping of left upper lid since birth with defective vision

\section{Pre Operative Evaluation}

Ptosis evaluation (MRD1 was $-2 \mathrm{~mm}$, LPS function was good, frontalis action was good, Marcus Gunn Jaw winking phenomenon was present Photographic and/or video documentation of eyelid position with opening, closing and sideto-side movements of the jaw (synkinetic movement) was done Bell's phenomenon was present No associated strabismus Slit lamp examination/ocular surface evaluation was WNL
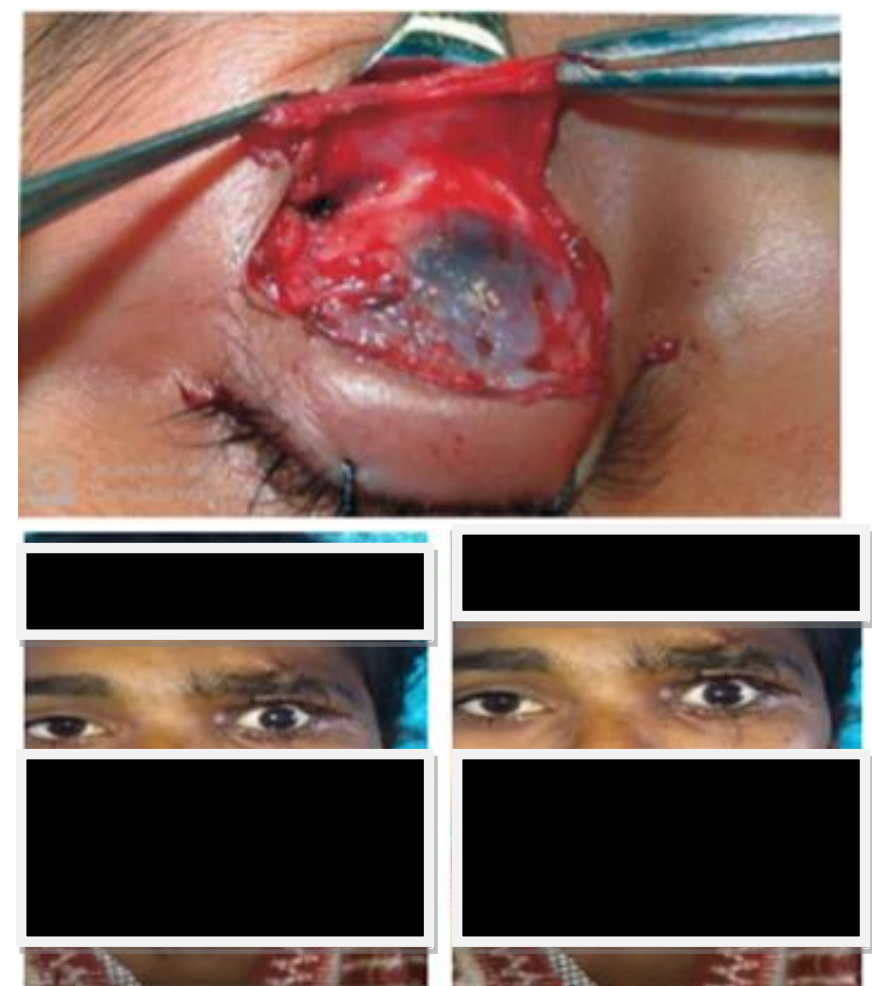

te

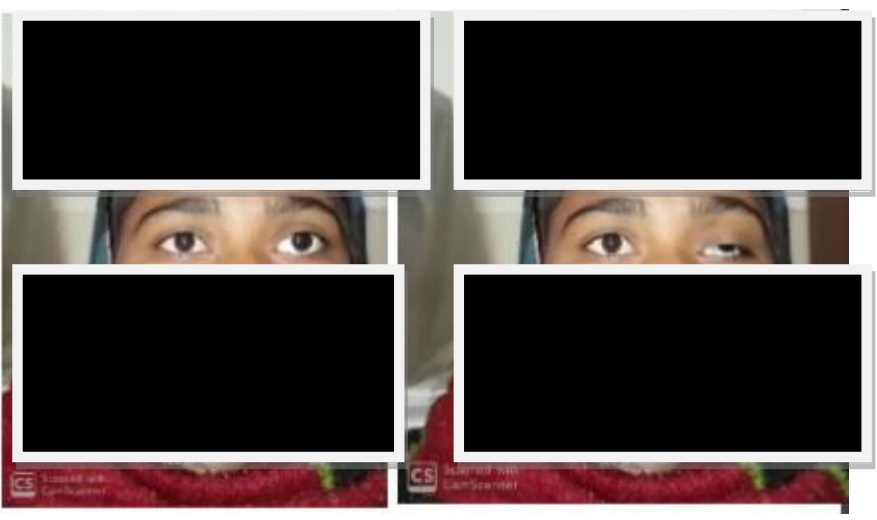

\section{Surgery}

Levator disinsertion and silicone frontalis sling was performed. Stab incisions are made above the brow with a 15 blade. These incisions are bluntly dissected open with artery forceps. A 15 blade is then used to make an incision along a small blepharoplasty marking... Dissection is then performed through the orbicularis muscle to the underlying orbital septum. Dissection then is carried out through the orbital septum to identify the underlying preaponeurotic fat. The preaponeurotic fat is demonstrated and dissected from the underlying levator aponeurosis and muscle. Dissection is carried out superiorly as far as possible at least to the level of Whitnall's ligament. Then levator aponeurosis was disinserted from the anterior surface of the tarsus. Following which all the layers were sutured layer by layer. This was followed by a standard Fox technique of sling surgery.

\section{Result}

In this case, levator muscle was disinserted and the eyelid was coupled to the frontalis muscle using a sling made of a synthetic material. By recruiting the frontalis muscle to raise the eyelids, this procedure relieved the dysfunctional levator from contributing to eyelid elevation.

\section{Discussion}

If the jaw winking phenomenon does not objectively improve with age or if the patient is unable to mask the synkinesis, levator disinsertion with frontalis suspension may be considered for treatment of this displeasing jaw wink. Unilateral 
surgery is preferred of the aberrantly innervated side to spare the normal side from surgical intervention. The primary benefit of surgery on both sides is to drive bilateral frontalis function when eyelid elevation is desire The surgical approach involves disinsertion of the levator aponeurosis from the tarsal plate Multiple approaches have been described including anterior and posterior approaches as well as extirpation of the muscle at the level of Whitnall's ligament and even to the orbital apex. . Our preferred technique for mild-to-moderate jaw wink is a unilateral, anterior approach levator disinsertion to the level of Whitnall's ligament. Frontalis suspension is then performed with silicone sling. Silicone sling affords the advantage of easy reversibility, and this is important especially in patients with reduced corneal protection (poor Bell's phenomenon).

\section{Conclusion}

The jaw-winking phenomenon is a congenital clinical entity characterized by involuntary elevation of a ptotic upper eyelid concomitant with various movements of the mandible. Following surgery, the lid lag, which was quite marked at the beginning, was much reduced after three months. The lagophthalmos was minimal. A good symmetrical lift with a good lid fold was obtained. Surgery for both eyes is not required as unilateral surgery gives good result. This method is extremely simple and required no special instruments

\section{References}

1. Ptosis surgery -Dr Arnab Biswas

2. Davis G, Chen C, Selva D. Macus Gunn syndrome. Eye. 2004; 18:88.

3. Bowyer JD, Sullivan TJ. Management of Marcus Gunn jaw winking synkinesis. Ophthal Plast Reconstr Surg. 2004; 20:92. 